\title{
Van Cleve, \\ The Bundle Theory \\ and Guise Theory
}

ERANCESCO ORILIA

Indiana University

Van Cleve argues, inter alia, that Castañeda's guise theory, ' because of its bundle-theoretic character, suffers from some of the old problems that tend to affiict bundle ontologies. I intend to show that guise theory meets all of Van Cleve's challenges. This will suggest that guise theory offers all the advantages of a bundle theory, without 1 ts traditional flaws.

\section{I}

Van Cleve (1985) considers the following three versions of the bundle theory: ${ }^{2}$

(BT1) (1) . . . a thing is a complex entity of which properties are the sole constituents, and (i1) . . . for a thing to have or exemplify a property is for that property to be a constituent of $1 t^{3}$

(BT2) A thing is nothing . . . but a bundle of properties. . . whose elements all stand to one another in a certain important relation . . (1.e.) co-instantiation" . . . The cardinal point about co-instantiation is that it is a contingent relation. That 18 , if two or more properties are co-instantiated, it is not in general necessary that this have been so."

(BT3) this version would decline to identify individuals with complexes of properties, offering instead to translate any statement about individuals into a statement exclusively about properties."

(BT1) and (BT2) are attacked on the basis of 8 ix traditional objections that are usually voiced against bundle theories. The first three really have to do with taking the crucial notion of bundle (or complex of properties) to be nothing (or little) more than the notion of set. I shall rehearse just one of them. In 
the words of Van Cleve: "there are many sets without corresponding things, e.g. the set being an alligator, being purple." I

Van Cleve holds that this kind of objection is fatal to (BT1) but he admits that (BT2) gets around them. He concedes, however, that (BT2) must surrender to the remaining three. I summarize them as follows:

Objection 4. (BT2) cannot account for the fact that things undergo changes.

Objection $\underline{5}$. It follows from (BT2) that all things have all their properties essentially.

Objection 6. (BT2) requires that the principle of the identity of indiscernibles (PII) is a necessary truth, but exceptions to PII are concelvable.

Van Cleve presents (BT3) as a possible bundletheoretic rejoinder to objections 1-6, but he submits that it falls prey to an argument ad personam: "I a defender of (BT3) ) . . . would have to believe. . . that there is no such thing as himself." I shall not discuss this here, for whatever the shortcomings of (BT3) are, the bundle-theorist need not resort to it as long as a more plausible alternative, such as guise theory. is still viable.

Van Cleve's unease with guise theory results from his classifying it as a (BT2)-theory. He does so by subsuming under his co-instantiation Castañeda's consubstantiation, as well as Russell's compresence and Goodman's togetherness. 10

These four notions do present many similarities. Yet, they also differ in important respects, so that they cannot really be said to play the same role."1 In particular, while compresence, togetherness and coinstantiation are alike in that they hold among properties, ${ }^{2}$ Castañeda's consubstantiation holds between entities of a different kind, namely, guises, that belong in the category of concrete individuals.

We should be grateful to Van Cleve for having indirectly suggested a comparative study of the systems associated with these notions, a study that would certainly be fascinating. Time and space does not allow me to do it here. I shall limit myself to a description of those features of guise theory which are relevant to the present discussion. This will allow us to see clearly why guise theory is a version of the bundle theory that survives objections 4-6 in perfectly good health.

\section{I I}

The fundamental datum on which guise theory is based is that ordinary physical objects such as tables and 
chairs are too complex to be experienced by us in their entirety. We can only experience guises or aspects of them. For example, when one says veridically that she/he sees a table, he/she is only seeing a side of the table and not the whole of it. To the extent that we regard the experience of a guise as an experience of a physical ordinary object, we should regard the guise as a concrete object and in that respect the guise must be distinguished from a mere set of properties.

In fact there is a qualitative difference between the experience of a set of properties and that of a concrete individual. If I am looking at the same time at a rose and at an alligator, we can correctly say, with Van Cleve, that in no sense I am seeing a pink alligator, although, in some sense, the set being pink, being an alligator can be sald to be in my visual field.

We must then admit that the "presence" of a set of properties within the content of an experience is not enough to experience a concrete individual. We can suppose however that a set of properties can be "enriched" by a concretizing factor, i.e., by what accounts for the concrete individuality of an individual as distinct from the abstractness of a set. We can call such a factor the concretizer or individuator. The concretizer can be formally described as an operator that takes sets of monadic properties as arguments. 13

Accordingly, if " $c$ " expresses the concretizer and $F_{1} \ldots$. . . Fn are monadic properties, a guise can be said to be of the form $c\left\{E_{1} \ldots\right.$. . . $\left.E_{n}\right\}$, where the set $\left\{E_{1} \ldots\right.$. . Fn\} is called the core of $c\left[E_{1} \ldots . . . F_{n}\right\}$. It is worth adding that since guises can be taken to be the referents of English definite descriptions, the conconcretizer can be said to be what 18 expressed by the English article "the" as it is used, e.g., in the expression "the Queen of England." I"

Note that the concretizer does not account for a concrete individual's being different from all other Individuals. In fact I did not say that every concrete individual has its own distinct concretizer. If this were so, the notion of a concretizer would differ only verbally from that of a bare substrate in which properties inhere. Though the concretizer is an operator and not a property, it is a universal in the sense that it is shared by all individuals in roughly the same sense in which the property red is shared by all red objects. Thus, guises can be different from each other only in virtue of the properties that constitute their cores. In this sense, guises are typical bundle-theoretic entities.

As we saw already, guises can be considered aspects of ordinary physical objects. At that juncture, the dichotomy bundle view vo. substrate view proposes itself again in the form of two possible options. The 
first consists of taking guises to be (partial) representations of particulars lying mysteriously beyond our reach. The second consists of taking ordinary physical objects to be merely structures or clusters of guises related to each other by the relation of consubstantiation. Castañeda emplatically chooses the second option and accordingly calls guise theory a "bundlebundle theory.

Consubstantiation is the contingent identity expressed by the English "is" in expressions such as

(1) the morning star is the evening star

(2) this piece of marble is Michelangelo's most beautiful statue

(3) every drop of water is a drop of $\mathrm{H} 20$.

We must then hold fast to the idea that consubstantiation is a relation that (i) holds between entities that can be categorized as concrete inclividuals, namely guises, and (ii) allows the "construction" of ordinary physical objects insofar as the latter are regarded as structures constituted by mutually consubstantiated guises. (These structures are characterized by certain important formal properties; as regards this the reader should consult the relevant works in the bibliography).

IV

We are now ready to tacke Van Cleve's objections one by one.

\section{Reply to objection 4 .}

Since Van cleve understands co-instantiation as a relation that contingently keeps together in a complex different properties at different times, he admits that

in the bundle theorist world, there can be plenty of change of one sort, namely change in the relational characteristics of properties."

Nevertheless, he laments that

If $F$ and $G$ are co-instantiated first with $H$ and later with $K$, so that the complex FGH is superseded by the complex EGK, what we have is replacement of one individual by another, not. change in the properties of one and the same individual. FGI is simply not identical with EGK. 17

Van Cleve is here implicitly acknowledging two important data: (i) a change presupposes a self-same 
subject of change and a notion of predication that allows us to say that such a subject is, say, $H$ at time $t$ and $K$ at time $t^{\prime}$. (1i) Not only properties, but concrete individuals can change. For example, we say that the morning star appears in the sky in the morning; it then disappears and reappears again at night.

Van cleve is right in thinking that with his complexes and his co-instantiation, he does not have enough "tools," so to speak, to account for the data. Guise theory on the other hand can account for these data since guises are the required concrete individuals that remain self-identical through change, and consubstantiation is the form of predication that allows 48 to make sense of their changing.

Let us note first that, according to guise theory, the contingent attribution to a guise $g$ of a property $P$ (that possibly does not belong in 1 ts core) is nothing more than the claim that $g$ is consubstantiated with the guise $g^{\prime}$ whose core is the core of $g$ union $P$. In other words,

(4) The Queen of England is happy

is to be parsed roughly as

(5) $C *$ (c \{being Queen of England\}, $c$ \{being Queen of England, being happy\}) (where " $C \star "$ symbolizes the notion of consubstantiation.)

Now suppose that (5) is true at time $t$ and that at times $t^{\prime}$ the Queen of England becomes unhappy. The truth of. (5) 18 then superseded by the truth of

(6) $C^{*}$ (c \{being Queen of England\}, c fbeing Queen of England, being unhappy\}).

Consequently, the cluster of consubstantiated guises comprising $c$ [being Queen of England, being happy 18 superseded by one that comprises $c$ \{being queen of England, being unhappy instead. 's But obviously the concrete guise c being queen of England\} has remained self-identical through this change.

This account heavily relies on the fact that guise theory is a bundle-bundle theory rather than gimply a bundle theory. But the fact that guise theory is bundle-theoretic twice over is overlooked if one assumes that consubstantiation (like Van Cleve's coinstantiation) is a relation that holds between properties, rather than between guises. It is an important point, though, because, although consubstantiational clusters can be "superseded" in much the same way in which Van Cleve's complexes can, this in no way hinges on recognizing in the guises the concrete unities of our experience that remain self-identical through the 
change induced by the contingent character of consubstantiation.

Reply to objection 5 .

Here is how Van cleve argues for the thesis that (BT2) is committed to deny that concrete objects can have contingent properties:

It will not be true of any individual that it might have existed with properties other than the ones it actually has: we cannot suppose that a complex whose constituents are $F, G$, and $H$ might have existed with $F, G$, and $K$ as its constituents instead. 19

Patently, Van cleve is implicitly acknowledging as a datum the fact that we can speak of a concrete individual as if we can re-identify it in a counterfactual situation in which it has, say, the property $K$ rather than the property $H$ that it in fact has. For example, we say that the morning star might not have had the property of appearing in the evening. Once more, this presupposes self-same subjects of re-identification and a notion of predication that allows us to attribute to them different properties under different (counter) factual conditions (or in different possible worlds, if you wish.)

Again, guises are sucl subjects and corsubstantiation is such a notion of predication, whereas Van cleve's complexes and co-instantiation cannot play these respective roles. Given the contingent character of consubstantiation, it is perfectly correct to say that a concrete individual such as the morning star might not have been consubstantiated with what it is in fact consubstantiated, e.g., the evening star. As it should be clear from the foregoing discussion, this is the same as saying, from the point of view of guise theory, that the morning star might not have had the property of appearing in the evening. 20

The contingent character of consubstantiation is also revealed by the fact that the guises that are in fact consubstantiated might have failed to be such, i.e., might have failed to exist. ${ }^{2}$ This is also a possibility for Van Cleve's complexes,22 but, as we have seen, other options as well are open for Castaneda's guises.

\section{Reply to objection 6 .}

In launching his objection 6 , Van Cleve is well aware, of course, that it suffices to count selfidentity (which he calls an "impure property") as a property to make the denial of PII absurd. He thinks, 
however, that such a move is not open to the bundle theorist:

Impure properties, is such there be, are ontologically derivative from individuals; individuals, if the bundle theory is true, are ontologically derivative from properties. One cannot have it both ways. Hence, the bundle theory cannot admit impure properties.23

Van Cleve's conclusion does not follow, for his last premise should be refected. Indeed, one must "have it both ways." Truly, the bundle theorist is committed to the ontological dependency of concrete individuals on the properties that constitute them as bundles of properties. But impure properties, 1.e. (if I understand Van Cleve's use of "impure") properties other than the ones that constitute the bundle, must "emerge," once a bundle is constituted.

This is obvious if one just considers that selfidentity must be a property that is true of any given object independently and over and above whatever properties have contributed to 1 ts being that given object. Van Cleve's contrast of impure vs. pure properties implicitly hints at such a datum.

Guise theory acknowledges it and accordingly distinguishes between internal and external forms of predication. The former" allows us to predicate of any given guise the properties that contribute to its constitution, as when we say, with Meinong, that even the round square $1 \mathrm{~s}$, in some sense, round. The latter allows us to predicate of any given guise, whatever properties can or must accrue to it, once the guise is constituted. Self-identity is but one case of a property that can be predicated externally.23 Consubstantiation is but another form of external predication in that, as we saw, it provides a means to predicate of guises properties that do not belong in their core. 26

The possibility of external predication makes guise theory a hierarchical ontology that has its foundations on a level of basic properties and operators ${ }^{27}$ on which successive stages of guises and properties rest, with each stage ontologically dependent on the preceding one. In fact, according to guise theory, from external predications one can obtain properties that can, in turn, contribute to the formation of new guises. For example, we can have "internal" self-identity and "internal" consubstantiational properties." (Therefore, a guise such as c lbeing a morning star, being selfidentical, being consubstantiated with the evening star\} 1s a legitimate guise, which is distinct from, and yet contingently the same as, c fbeing a morning star\}).

This sharply distinguishes guise theory from what might be called the "flat" version of the bundle theory 
that Van cleve seems to have in mind, a version in which no new property can be "ontologicaliy posterior" to the constitution of bundles.

\section{V}

Van cleve's stand against the bundle theory is based on data that must undoubtedly be taken into account. This demonstrates his keen philosophical sense. Guise theory, however, provides a bundle-theoretic account of such data. It thereby avoids the postualtion of unknowable substrates whose mysteriousness many philosophers, e.g. Hume and Russe11, 29 have lamented. 30

NOTES

"Van Cleve, "Three Versions of the Bundle Theory," Philosophical studies 47, 1985, pp. 95-107. Guise Theory is expounded in Castañeda 1974, 1975a, 1977. A quick but sufficiently detailed introduction to it is provided by Plantinga 1983, part I.

"The labels "(BT1)," "(BT2)," and "(BT3)" are mine.

${ }^{3}$ Van Cleve 1985, p. 95.

-Van Cleve 1985, p. 97.

sVan Cleve 1985, p. 98.

'Van Cleve 1985, p. 103.

'See Van Cleve 1985, p. 95.

'Van Cleve 1985, p. 96.

'Van Cleve 1985, p. 105.

${ }^{\circ}$ Van Cleve 1985, p. 97.

${ }^{11}$ Contra Van Cleve 1985, note 7, p. 106.

${ }^{12}$ Although we should perhaps more properly speak, in the case of Russell and Goodman, of phenomenal qualia (cf. Russell 1948, p. 294, and Goodman 1977, p. 144, respectively.)

"Castañeda's discusses the concretizer in Castaneda 1975, and 1974, pp. 4-5 and 12-17. 
"Contra Van Cleve we should thus say that the concretizer and not consubstantiation (to be described below) is guise theory's answer to (BT1)'s main problem, namely that concrete individuals are not mere sets of properties. However in fairness to Van cleve it must be said that the notion of consubstantiation allows us to distinguish between mere sets of guises and sets of guises whose members are all aspects of one physical object.

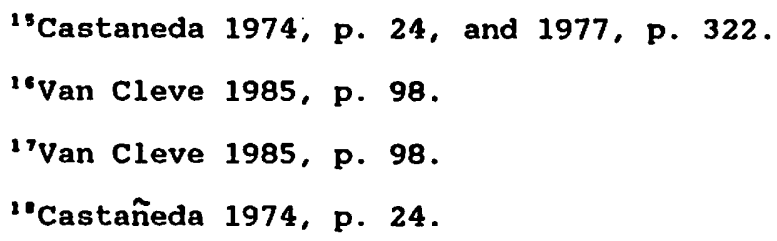

'If, at time $t$ ', the cluster of guises $c$, comprising the guise $g$, is "superseded" by the cluster $C^{\prime}$ ' that comprises the guise $g^{\prime}$ instead of the guise $g$, then, certainly, $C^{\prime}$ is distinct from $C$. Nevertheless, $C$ and $C^{\prime}$ can be said to be related by a relation akin to 1 dentity, but weaker than $1 t, 1 . e .$, transubstantiation (cf. Castañeda 1974, p. 26). Castañeda has never worked out in detail the laws governing transubstantiation. Unfortunately, to do it here would take us too far afield.

${ }^{20}$ Van Cleve 1985, p. 99.

${ }^{21}$ Note, however, that Castan̂eda did never explicitly consider a guise-theoretical treatment of modalities (such as the possibility expressed by the English "might" in "the morning star might not have had the property of appearing in the morning"). Nevertheless, we can speculate that two distinct consubstantiational clusters belonging to two different possible worlds can be realted by something analogous to transubstantiation, provided the two clusters have certain guises in comsnon (which guises might depend on the context and on assumed standards). We might call such a relation countersubstantiation (since it can be used for a guise-theoretical account of counterfactuals) or simply transubstantiation with respect to possible worlds. To expand on this here would take me beyond my present concern.

${ }^{22}$ For the relation between consubstantiation and existence see Castañeda 1974, p. 13 and p. 15, and 1977, p. 323.

2 'Van Cleve, 1985, p. 99.

2 "Van Cleve 1985, p. 96. 
${ }^{25}$ That is, Meinongian predication (cf. Castaneda, 1974, p. 11).

"Castañeda 1974, p. 12. Castañeda's contrasting therein the notion of property and the notion of entering a fact, corresponds, I take it, to Van Cleve's contrast of pure and impure properties.

"'conflation and consociation are other forms of external predication (ç. Castaneda 1974, pp. 17-20).

2 "Such as the concretizer and the set forming operator.

29 it can be seen from Castaneda's analysis of the Meinong-Russell debate (cf. Castaneda 1974, p. 21).

'See, e.g.. Hume 1975 Book I, part I, sect. VI, pp. 15-17, and Russell 1948, p. 294.

"I am grateful to Professor Hector-Neri Castañeda and to an anonymous referee for helpful comments on previous drafts of this paper. I also wish to thank Karin Usadi for some stylistical suggestions.

\section{B I BLIOGRAPHY}

Castañeda, H. -N.: 1974, "Thinking and the structure of the World," Philosophia 4, pp. 3-40.

Castafieda, H. -N.: 1975, "Individuation and NonIdentity: A New Look," American Philosophical Quarter1y 2: 131-140.

Castañeda, H. -N.: 1975a, "Identity and Sameness," Philosophia 5, pp. 121-150.

Castan̂eda, H.-N.: 1977, "Perception, Belief and the Structure of Physical Objects and Consciousness," Synthese 35, pp. 285-351.

Goodman, N.: 1966, The structure of Appearance (Reidel, Dordrecht.)

Hume, D.: 1975, A Treatise of Human Nature (Clarendon Press, Oxford).

Plantinga, A.: 1983, "Guise Theory" in Tomberlin, J. E. (ed.): Agent, Language and the structure of the World (Hackett Publishing Company, Indianapolis). 
Russe11, B.: 1948, Human Knowledge: Its Scope and Limits (Simon and Schuster, New York).

Van Cleve, J.: 1985, "Three Versions of the Bundle Theory," Philosophical studies 47, pp. 95-107. 